\title{
Light Activation of Contractile Roots of Easter Lily
}

\author{
Mordecai J. Jaffe and A. Carl Leopold ${ }^{1}$ \\ The Boyce Thompson Institute for Plant Research, Cornell University, Ithaca, NY 14853
}

AdDitional INDEX words. bulb movement, blue light, exodermis

\begin{abstract}
Contractile roots provide for a type of movement in plants that occurs in many plant species but has been given little attention. In the case of Easter lily (Lilium longiflorum Thunb. cv. Nelly White), root contraction serves to pull a bulb down into the soil where environmental conditions are more constant. The contraction is evidenced by a formation of epidermal wrinkles, starting at the base of the root and advancing toward the root tip. The movement function occurs in shallowly planted materials, is lessened at deeper locations, and ceases at a vermiculite depth of $\approx 15 \mathrm{~cm}$. Examination of the cell shapes and volumes in the contracting sector indicates that movement of the bulb in the soil is achieved by a hydraulic shift in cortical cells. Root contraction is stimulated by light. Perception of the light stimulus does not occur in the root but occurs in the bulblet or possibly in the subtending leaf. Responsiveness to light fades with aging of the root, and experiments with light of different wavelengths indicate that the contraction response is preferentially triggered by blue light.
\end{abstract}

The autonomous movement of plant stems or bulbs down into the soil occurs through the contraction of roots. This type of movement was first noted by Theophrastus $(\approx 300 \mathrm{BCE})$ and was described more recently by Tittmann (1819) in roots of Daucus carota L. Contractile roots (CR) were first seriously studied by De Vries $(1880)$ and Rimbach $(1898,1926)$ and reviewed by Galil (1980). They have been reported to occur in $>400$ species of both monocotyledonous and dicotyledonous supertending organs, such as bulbs, corms, hypocotyls, (e.g., De Vries, 1880; Galil, 1980; Rimbach, 1902, 1926). Contractile roots pull these organs down through the substratum until they reach a location that is presumed to be advantageous in terms of insulation from hostile surface environments. Contractile roots also may pull bulblets away from the bulb scale, providing the benefit of dispersal.

In some species, the movement of the bulb into the substrate diminishes at greater depth. The sensing of depth has been suggested to occur by light reaching either the bulb or the leaf that arises from the bulb (Iziro, 1983; Putz, 1996a; Putz et al., 1997; Rimbach, 1898). Temperature cycling also may enhance root contraction in some species (Halevy, 1986; Iziro, 1983; Iziro and Hori, 1983a; Jacoby and Halevy, 1970; Putz, 1996b).

Among the types of plant movement, the contractile movement of roots in causing underground movement of plant parts is a novel observation, although it has been noted in $>400$ species. The paucity of attention given to contractile movement (Leopold and Jaffe, 2000) makes it an appealing subject for study. Herein we describe some physiological and structural factors that contribute to the contraction of CR in Easter lily: the cellular modifications involved in the contraction and the stimulation of contraction by light.

\section{Materials and Methods}

Plant material. Experimental material involved bulbs of 'Nellie White' Easter lily. Scales from 1-year-old, previously

Received for publication 19 Sept. 2005. Accepted for publication 15 Mar. 2007. We thank Prof. William Miller for supplying us with the lily mother bulbs used in this study. We are grateful to Prof. Randy Wayne for allowing us the use of his physiological dark room.

${ }^{1}$ Corresponding author. E-mail: ACL9@cornell.edu. vernalized, mature bulbs were removed sequentially and layered horizontally, with the adaxial side down, on mediumgrade vermiculite. After 6-8 weeks, the scales formed bulblets, and the bulblets generated roots (Fig. 1C). The appearance of a bulblet with a single CR is shown at the right in Fig. 1A. Both nutrient (noncontractile roots) and CR were formed, with the CR predominating.

The bulblets were separated from the scales, and any leaflets were removed, leaving a bulblet-root unit as shown in Fig. 1A. Most experiments were done with the bulblet-root unit planted in wet medium-grade vermiculite. For studies of the dynamics of the root development, individual bulblet-root units were mounted on discs of insulation material, with the roots protruding downward through holes, and floated on water where the root development could be monitored. Light was provided by six $40-\mathrm{W}$ fluorescent lamps. Irradiance was $100 \mu \mathrm{mol} \cdot \mathrm{m}^{-2} \cdot \mathrm{s}^{-1}$.

Root contraction begins at the base of the root, where it is attached to the bulblet. During contraction, the epidermal cells do not shorten as the cortical cells do, and consequently contraction produces wrinkling of the outer layers of the root (Fig. 1B). As the root contracts, the wrinkling advances down the shank of the root, providing an easily measured signal of the progress of contraction. Contraction was measured using the CR stage (defined below), the change in root length, as well as by the extent of wrinkle formation per centimeter. The progressive changes are defined as six successive stages: Stage I, elongating roots show no swelling or wrinkling; Stage II, roots show swelling but no wrinkling; Stage III, roots with continued swelling and the first detectable wrinkling $(1-3$ wrinkles $/ \mathrm{cm})$; Stage IV, roots fully swollen and contracted $(>3$ wrinkles $/ \mathrm{cm})$; Stage V, roots showing early stages of senescence (yellowing color, lessening turgor, and collapse of wrinkles); Stage VI, cortex becomes hollow and the root dies.

ORgaN AND TISSUE PARTICIPATION IN ROOT CONTRACTION. For the time course of contraction, the root length was measured at 3-d intervals. When contraction wrinkles were first observed, the previous 3-d measurement was called day zero, and contraction was followed as change in overall length of the root during the subsequent $15 \mathrm{~d}$. In experiments on the locus of the contraction signal, either the bulblet or the 2-mm root tip was excised with a scalpel, and contraction was compared with non-excised controls. To control for possible gravitational effects, 
excised roots were held vertically in tap water or laid horizontally in tap water. To determine the linear amount of wrinkling, the photo-image of the root was enlarged and printed out. A map distance reader was run over the edges of the convolutions to determine the total length of the edge within $1 \mathrm{~cm}$ of root length.

For measurements of the relation of contraction to cell dimensions, hand-cut cross- or longitudinal sections were immersed in 1\% sodium hypochlorite (to remove cell contents), rinsed $3 \times$ with distilled water, washed in $1 \%$ acetic acid, and mounted in water for observation at 10× magnification (Gray, 1958). Dimensions (length $\times$ width $\times$ breadth) of endodermal, inner, middle, and outer cortical parenchyma, exodermal and epidermal cells were measured from video micrographic images. At least 20 cells for measured for each tissue. Within the stele, the helices of the xylem wall thickenings were counted (turns $/ 50$ $\mu \mathrm{m})$. Toward the end of the life cycle of a CR, cortical cells undergo autolysis, leaving air spaces. When these occurred, the volumes of the air spaces were estimated by measuring the length $\times$ width $\times$ breadth of the spaces. Cell volumes were estimated by assuming a cylindrical cell shape using Eq. [1].

$$
\text { Cell volume }\left(\mu \mathrm{m}^{3}\right)=(R+T / 4)^{2}(2 \pi L)
$$

where $R$ is the radial diameter, $T$ the tangential diameter, and $L$ the longitudinal length of the cell.
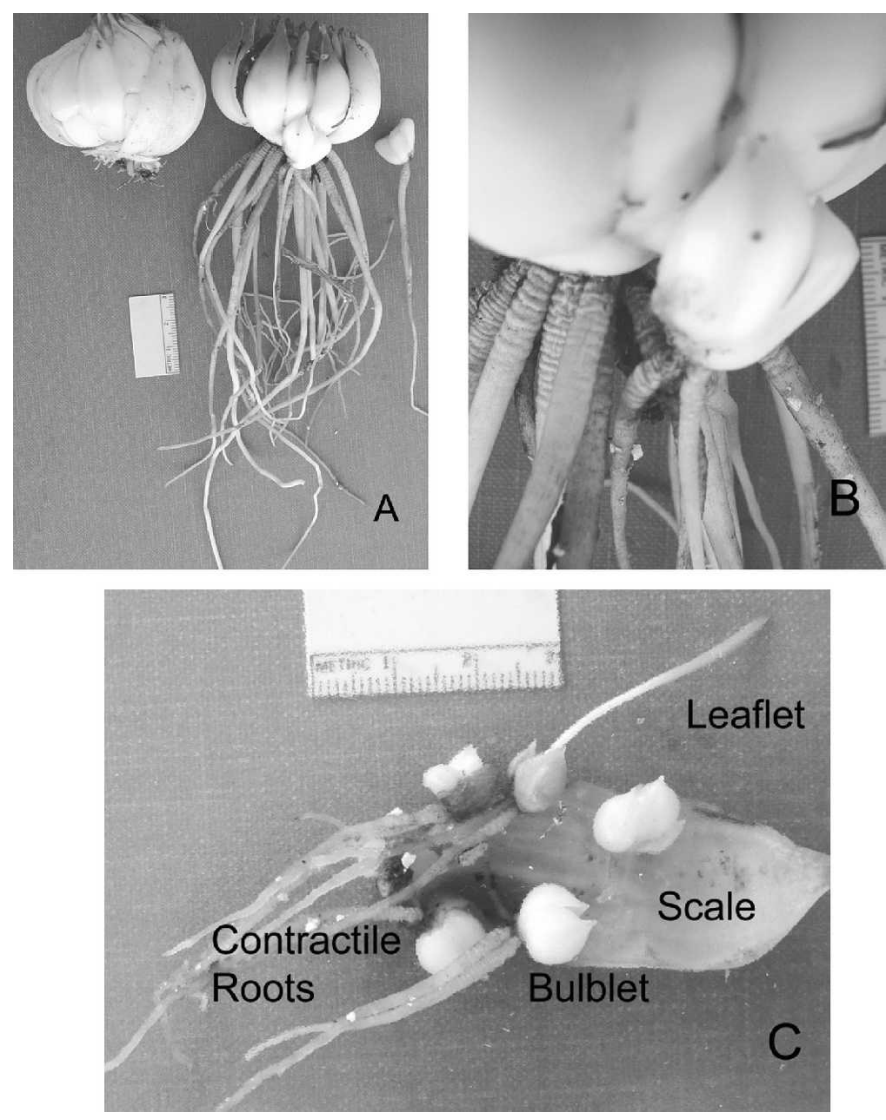

Fig. 1. Appearance of Easter lily mother bulb and bulblets. (A) Mature mother bulb before and after root development. Note a bulblet formed on a scale of the middle bulb. On the right is a single bulblet with a contractile root (the basic experimental unit in this study). (B) Closeup of the base of the mother bulb, showing wrinkled bases of contractile roots. (C) Closeup of a single scale with several bulblets developing on it. Note the contractile roots pointing left and a leaflet pointing right.
DEPTH PERCEPTION. We examined the CR performance as a function of planting depth, using inverted 2-L plastic soft-drink bottles $(30 \mathrm{~cm}$ tall, $10 \mathrm{~cm}$ in diameter) with the flat bottom removed. The mouth of the bottle was covered with cheesecloth, and the sides were wrapped in aluminum foil to prevent light

Table 1. Progressive change of contractile roots of Easter lily occurs through successive stages from youngest to oldest roots. ${ }^{\mathrm{z}}$

\begin{tabular}{lll}
\hline $\begin{array}{l}\text { Age sequence } \\
\text { of roots }\end{array}$ & Stages & $\begin{array}{l}\text { Numerical } \\
\text { mean } \pm \mathrm{SE}\end{array}$ \\
\hline 1. (Youngest roots) & I to III & $2.5 \pm 0.10$ \\
2. & IV & $4.0 \pm 0.02$ \\
3. & IV to V & $4.3 \pm 0.04$ \\
4. (Oldest roots) & V to VI & $5.1 \pm 0.08$
\end{tabular}

${ }^{\mathrm{z}}$ Mean values at successive stages are presented as numerical means \pm $\mathrm{SE}$; each data point is the mean for 6-10 bulblets, replicated three times.
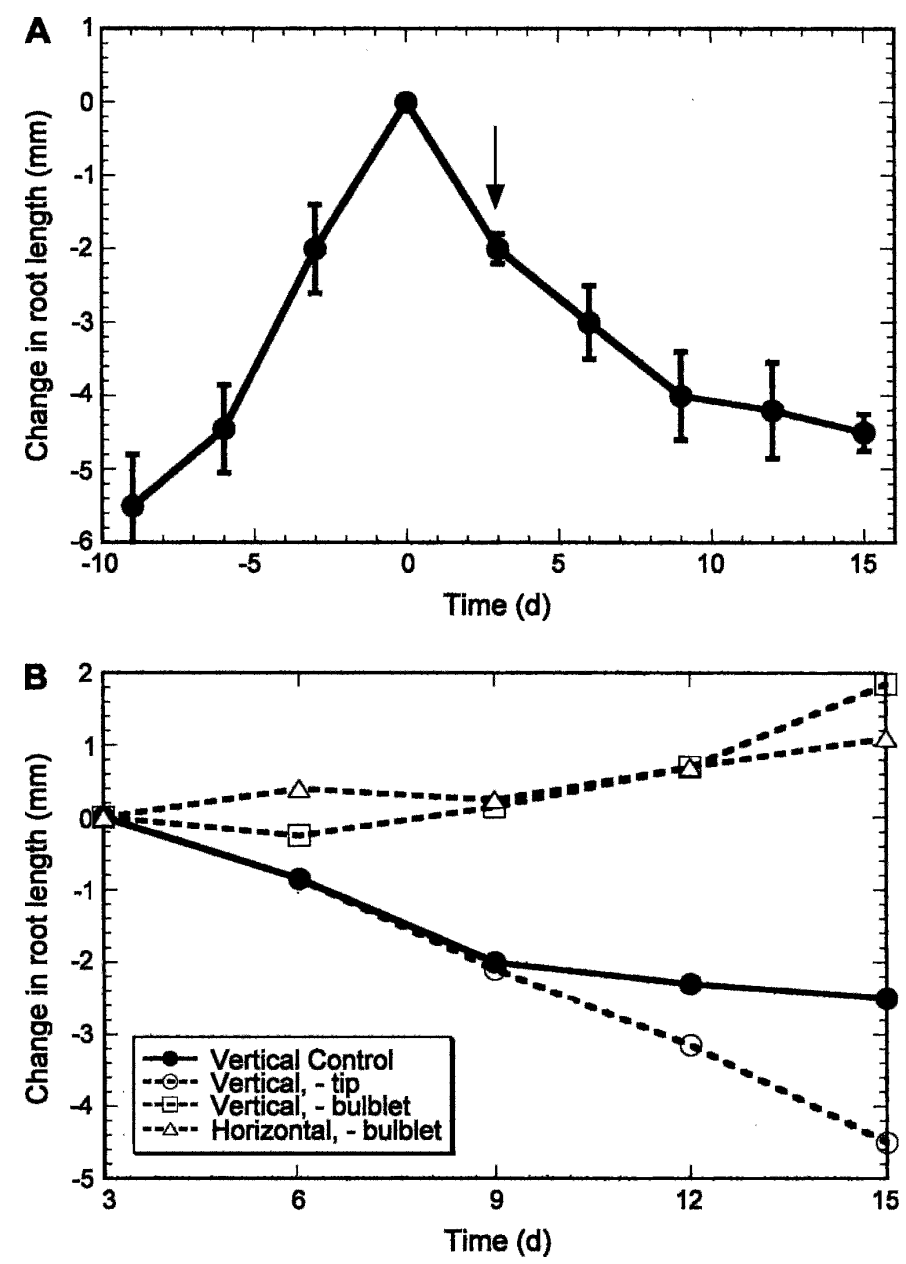

Fig. 2. Kinetics of root contraction of Easter lily roots. (A) Changes of root lengths, after $9 \mathrm{~d}$ of growth by elongation followed by $15 \mathrm{~d}$ of root contraction. Contraction time is taken to start $3 \mathrm{~d}$ before the first measured shortening (arrow) (data of 20 roots normalized to zero change). (B) Comparison of the root length during contractile growth for $15 \mathrm{~d}$ compared with three treatments: root tip removed (- tip), root severed from the bulblet (- bulblet), and root and held in horizontal position. Excision of the root tip did not prevent root contraction, severance from the bulblet prevented contraction, and isolated roots were unaffected by a horizontal orientation. At day 12, the differences between controls and severed root treatments were significant by $t$ test at $P \leq 0.03$. 
from entering from the side. Each inverted bottle was filled with medium-grade vermiculite, with 15 scales planted at each of four depths $(1,5,10$, or $15 \mathrm{~cm})$. Four such bottles were incubated in a growth chamber set at $16 \mathrm{~h} / 8 \mathrm{~h}$, and $23 / 10^{\circ} \mathrm{C}$ day/night. Light was provided by eight fluorescent bulbs (Sylvania, Danvers, MA), and irradiance at the soil level was $30 \mu \mathrm{mol} \cdot \mathrm{m}^{-2} \cdot \mathrm{s}^{-1}$. Irradiance was barely measurable at $0.01 \mu \mathrm{mol} \cdot \mathrm{m}^{-2} \cdot \mathrm{s}^{-1}$ beneath $1 \mathrm{~cm}$ of wet vermiculite, using a quantum radiometer (model LI-185A; LI-COR Biosciences, Lincoln, NE). The radiometer registered no measurable irradiance reaching the scales at other lower depths. The containers were subirrigated with tap water three times per week. After 3 months, the rooted bulblets were recovered and root measurements made. The planting depth experiment was replicated three times.

EFFECT OF Light on CONTRACTION. To study the light effects on contraction, scales were planted $1 \mathrm{~cm}$ below the surface of medium vermiculite in pots, four pots were placed in a greenhouse $\left[25^{\circ} \mathrm{C}, 64 \%\right.$ relative humidity $\left.(\mathrm{RH})\right]$ and another four in the darkroom $\left(23.5^{\circ} \mathrm{C}, 61 \% \mathrm{RH}\right)$. The plants in the darkroom were watered in the dark under a green safelight. After 3 months, the scales were removed and data recorded on the bulblet sizes, lengths of roots and leaflets, as well as the amount of contraction (wrinkles/cm).

In an additional experiment, the dynamics of root contraction was measured after various periods before and after transfer to light, starting at various stages of CR development. Bulblets on circles of insulation material were placed on floating disks with roots in tap water, as described above. These were held in the dark for $20 \mathrm{~d}$, and measurements were taken every $4 \mathrm{~d}$ in dim green safe light. On day 20, half of the jars were placed in the light $\left(100 \mu \mathrm{mol} \cdot \mathrm{m}^{-2} \cdot \mathrm{s}^{-1}\right)$ and measurements taken every $2 \mathrm{~d}$ for $10 \mathrm{~d}$ or until the completion of the root's life cycle. The measurements included root length, number of wrinkles per basal centimeter of the roots, and CR stage. Seven to nine roots were studied at each starting stage (Stage I, II, III, or IV). The experiment was performed in triplicate.

We estimated the effects of light quality on contractility using light filters. Bulblet-root units were floated on water, in chambers were irradiated continuously by light of various colors: ultraviolet A (UV-A), blue, green, red, or far-red using broad-band filters (Carolina Biological Supply Co., Burlington, NC). UV-A irradiance at $365 \mathrm{~nm}$, was provided by a lamp (model ENF-280C; Spectroline Co., Westbury, NY). The transmission spectra of the filters peaked at 450 , 520,660 , and $750 \mathrm{~nm}$, respectively, with bandwidths at half-height averaging $30 \mathrm{~nm}$. The radiant fluxes at the bulblet levels were 0.17 $\mu \mathrm{mol} \cdot \mathrm{m}^{-2} \cdot \mathrm{s}^{-1}$ for UV-A; 0.25 $\mu \mathrm{mol} \cdot \mathrm{m}^{-2} \cdot \mathrm{s}^{-1}$ for blue and far red; and $0.76 \mu \mathrm{mol} \cdot \mathrm{m}^{-2} \cdot \mathrm{s}^{-1}$ green and red. A higher fluence rate of UV-A killed the roots.

To determine the duration of light needed to induce contractility, similar preparations were incubated in the chamber under the blue filter for different photoperiods, using a compact fluorescent lamp (model 29105, Soft White Deluxe; Sylvania); irradiance at the bulblet $=0.1 \mu \mathrm{mol} \cdot \mathrm{m}^{-2} \cdot \mathrm{s}^{-1}$. Changes in both contractile stages and amount of wrinkles $/ \mathrm{cm}$ were measured. The experiment was replicated 3 times.

\section{Results}

The use of rooted bulb scales of Easter lily provided uniform clonal vegetative propagules for the study of root contraction. Individual scales formed bulblets from which roots emerged after 8-10 weeks. Both nutrient and CR developed, with the CR predominating.

The downward movement of a bulb is produced by the combined contraction of multiple CR. Table 1 shows the progression of contraction stages. As one root may be starting to contract, others are contracting and collectively pulling the bulblet down.

Organ and tissue participation in contraction. The progress of contraction in individual roots was followed as the changes in growth from elongation into contraction over a 15-d period as shown in Fig. 2A. Root length increased during
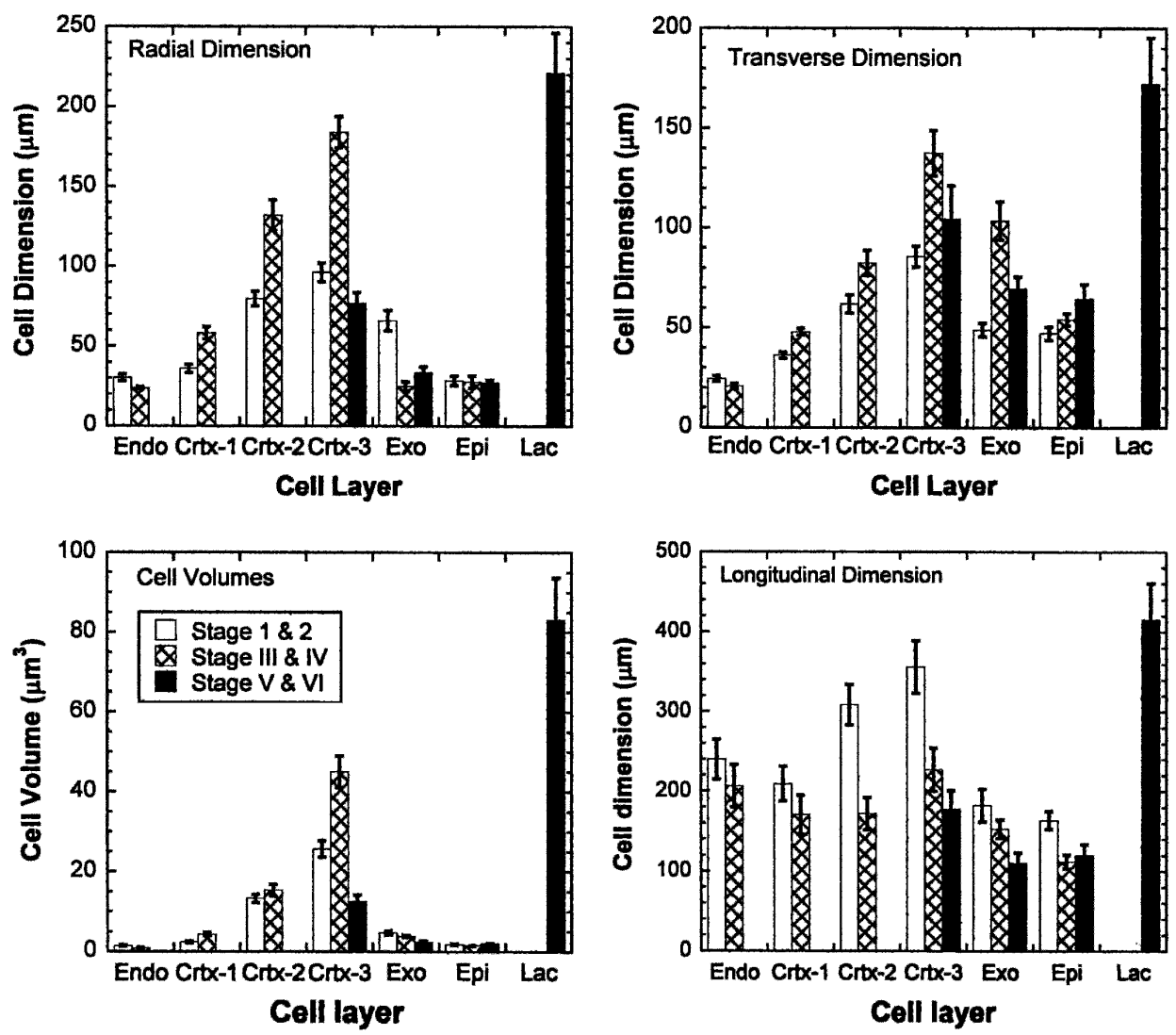

Fig. 3. Changes in cellular configuration occur as Easter lily root contraction advances. Dimensions are presented for endodermal cells (Endo), three levels of cortex cells (Crtx-1 to Crtx-3), exodermis cells (Exo), and epidermal cells (Epi) as contraction proceeds from Stage I to Stage IV and then to Stage V and Stage VI. Formation of lacunae (Lac) is also estimated. Radial dimensions (upper left), transverse dimensions (upper right), and longitudinal dimensions (lower right) were used to calculate cell volumes during contraction (lower left). For each datum, the SE is indicated. 
the $9 \mathrm{~d}$ before contraction, and then contracted over a subsequent $15 \mathrm{~d}$, during which total contraction of $>4 \mathrm{~mm}$ was achieved. This is a contraction rate of $0.27 \mathrm{~mm} \cdot \mathrm{d}^{-1}$.

To determine whether the contraction signal originated from the root, root tip, or bulblet, an experiment was carried out (Fig. 2B) using roots from which the tip $2 \mathrm{~mm}$ had been removed or the bulblet had been removed. Tip removal did not hinder contraction, but removal from the bulblet essentially prevented contraction. The similar lack of contraction when the roots were held in a vertical or horizontal orientation suggests no involvement of gravity. The data suggest that the signal for contraction is not generated from the root itself or the root tip, but the contraction signal comes from the bulblet (or its supertending leaflet).

Changes in cell dimensions are involved in root contraction as shown in Fig. 3. The data show longitudinal shortening of cells, concentrated in the cortical cells as contraction proceeds from Stage I and II to Stage V and VI (Fig. 3, lower right). Cell shortening was especially evident in the outer layers of cortical cells (Crtx-2 and Crtx-3). This was associated with increases in both radial and transverse dimensions (Fig. 3, upper left and right). These changes collectively resulted in increases in cell volume from Stage I to IV (Fig. 3, lower left), particularly in the outer cortical cells (Crtx-2 and Crtx-3). It seems evident that the swelling and shortening of cortical cells (Crtx-2 and Crtx-3) cause contraction of the root.

Because the "skin" of the root (composed of the epidermal and exodermal cells) can apparently neither swell nor shorten, the outer region is forced to become wrinkled as contraction proceeds. The cells of the stele apparently shorten by longitudinal compression of their cell walls, as evident from counts of the helices in xylem wall thickenings, which reveal increases from $12.2 \pm 0.8$ turns $/ 50 \mu \mathrm{m}$ in Stage I and II to $20.8 \pm 1.3$ turns/ $50 \mu \mathrm{m}$ in Stage III and IV. Therefore, root contraction imposes a major compaction of the stele. After contraction, the cortical cells begin to die (Stages V and VI), resulting in the appearance of air spaces.

By measuring the convolutions of the wrinkled surface from video images of longitudinal sections, we determined that, at the base of Stage III roots just beginning to contract, a $0.57 \pm$ $0.03-\mathrm{mm}$ stretch of "skin" shortens to $0.43 \pm 0.02 \mathrm{~mm}$, so that each wrinkle represents a shortening of $25 \%$. In Stage IV roots, a $0.55 \pm 0.04-\mathrm{mm}$ stretch of "skin" shortens to $0.26 \pm 0.03 \mathrm{~mm}$ at each wrinkle. At this stage, then, each wrinkle represents a cell shortening of $>50 \%$.

DEPTH PERCEPTION. When Easter lily scales were planted in vermiculite at various depths (from 1 to $15 \mathrm{~cm}$ ), the actual movement of the bulblet was inverse to the planting depth (Fig. 4; Table 2). The deeper the scales were planted, the less was the downward movement of the developing bulblets, until at a

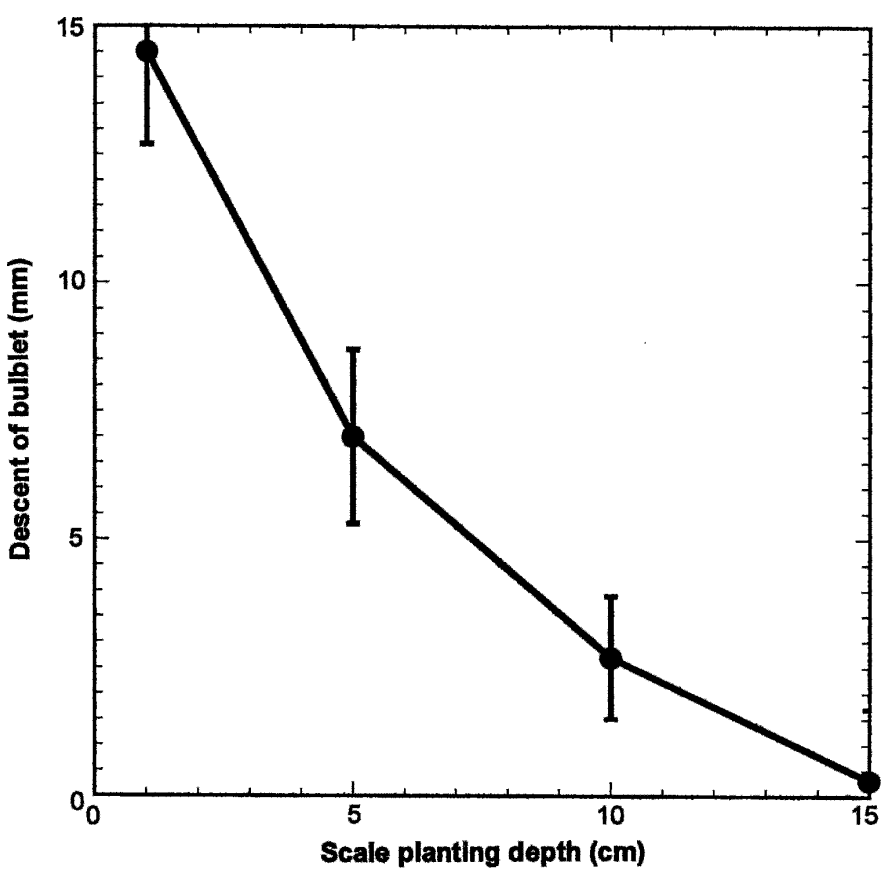

Fig. 4. Planting Easter lily scales at greater depths of vermiculite (from 1 to 15 $\mathrm{cm}$ ) results in decreased bulblet movement into the medium. Data are for 15 scales at each depth with four replicates. The best-fit equation of the curve is $y=0.07 x^{2}-2.1 x-16.3$.

Table 2. Effects of planting depth of Easter lily scales on contraction of contractile roots (CR), and various factors ( \pm SE). ${ }^{z}$

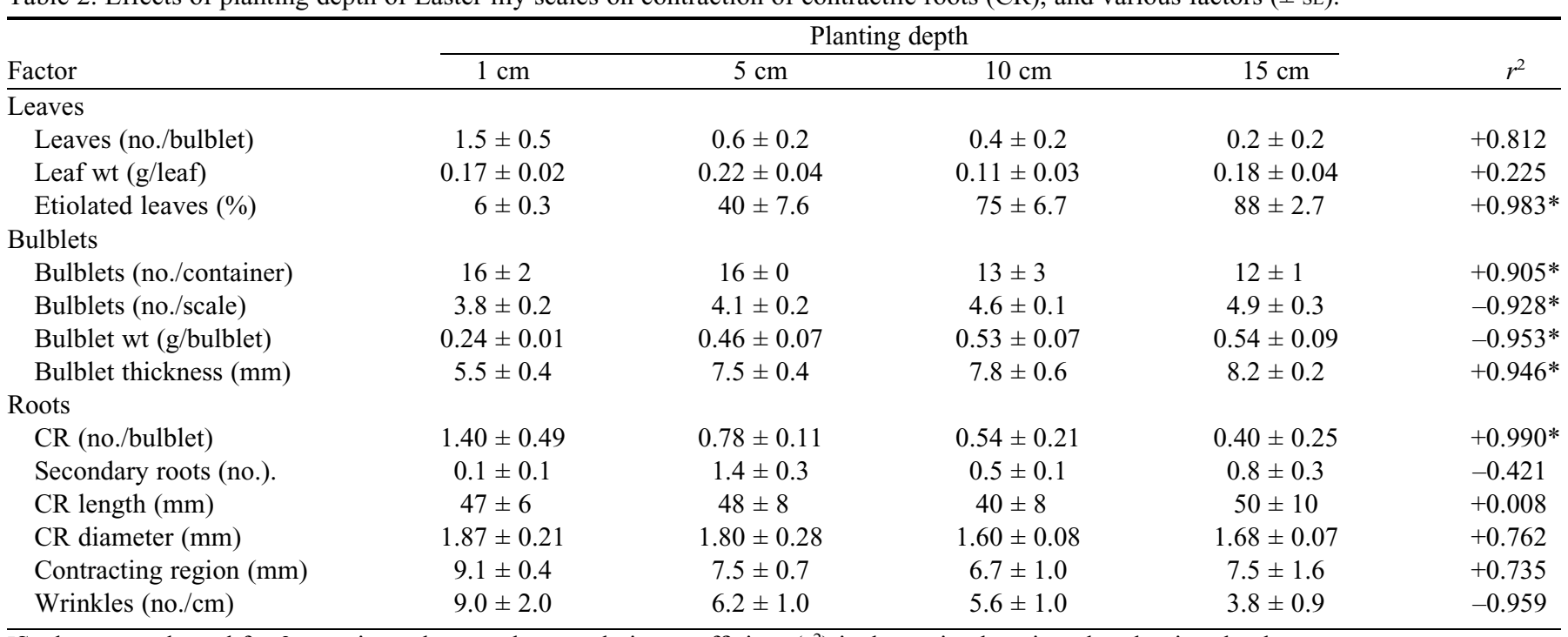

${ }^{\mathrm{z}}$ Scales were planted for 3 mo.; in each case, the correlation coefficient $\left(r^{2}\right)$ is determined against the planting depth.

*Significant at $P \leq 0.05$ by $t$ test. 
depth of $15 \mathrm{~cm}$ there was essentially no downward movement. As might be expected, the distance that the bulblets were pulled down was positively correlated with the number of CR per bulblet (Table 2). At increasing depths of planting, the bulblet weight was increased as well (Table 2), and there was an increasing growth of etiolated leaflet (Table 2).

There were more secondary roots produced by CR than by nutrient roots, but planting depth had little effect on nutrient roots. At all depths, the $\mathrm{CR}$ were thicker than the nutrient roots (data not shown).

The shallowest bulblets produced CR promptly, while those at deeper planting took longer and CR were less abundant (Table 2). Both CR production and its contractile function were decreased at greater depths. Both the length of the wrinkled part of the root and the frequency of wrinkles are negatively correlated with depth of planting (Table 2). Thus movement of the bulb and the forces of root contraction decline at increasing depths.

THE ROLE OF LIGHT. The association of root contraction with depth of planting suggests a role for light in signaling the contractile process. When scales were kept in the dark, they underwent some autolysis, but they developed little or no contraction (Table 3). The size of the bulblets was not altered by light, but the nutrient roots (nonCR) were longer under light. There was no downward movement of the bulblets in the dark.

In another effort to study the role of light perception, the bulblets of bulblet-root units preparations were covered with aluminum foil and the preparations were floated on water for $12 \mathrm{~d}$. Exclusion of light from the bulblet by aluminum foil prevented subsequent root contraction (Fig. 5). Bulblets kept in the light (without foil) showed contraction, whether estimated as changes in the CR stage (Fig. 5A) or measured by the number of wrinkles (Fig. 5B).

To further examine the role of light, bulblets with $\mathrm{CR}$ at different stages were held in the dark for $20 \mathrm{~d}$ and then transferred to the light at different stages (Fig. 6). In all cases, there was hardly any contraction in the dark and steady root contraction in the light. As soon as the Stage II and III plants were placed in the light, the roots started to contract, but the Stage I plant roots did not. This light effect was very weak in

Table 3. Comparison of light versus darkness effects on Easter lily root contraction. ${ }^{\mathrm{z}}$

\begin{tabular}{lcc}
\hline Observation & $\begin{array}{c}\text { Greenhouse } \\
(\text { mean } \pm \mathrm{SE})\end{array}$ & $\begin{array}{c}\text { Darkroom } \\
(\text { mean } \pm \mathrm{SE})\end{array}$ \\
\hline Scales surviving (no.) & $11.5 \pm 0.9$ & $7.8 \pm 1.9$ \\
Depth of bulblet & & \\
$\quad$ movement (cm) & $2.3 \pm 0.2$ & $0.0 \pm 0.1$ \\
Bulblets (no./container) & $28 \pm 3$ & $19 \pm 1$ \\
Bulblet width (mm) & $12.5 \pm 0.9$ & $12.2 \pm 0.2$ \\
Leaflets (no./bulblet) & $0.6 \pm 0.3$ & $0.0 \pm 0.0$ \\
Roots (no./bulblet) & $2.2 \pm 0.1$ & $1.0 \pm 0.04$ \\
Root length (mm) & $67 \pm 4$ & $31 \pm 6$ \\
Wrinkled region (mm) & $11.1 \pm 0.9$ & $0.3 \pm 0.1$ \\
Contraction (wrinkles/cm) & $14.0 \pm 0.3$ & $0.3 \pm 0.1$ \\
Contractile stage & & $\mathrm{I}$ \\
$\quad$ of roots (mode) & $\mathrm{IV}$ & \\
\hline
\end{tabular}

${ }^{\mathrm{z}}$ Bulb scales were planted in vermiculite, $1 \mathrm{~cm}$ below the surface, 12 scales in each $17.8-\mathrm{cm}$ diameter pot, four pots/treatment. Scales, leaves, bulblets, and roots were measured after $3 \mathrm{mo}$. in greenhouse versus darkroom.
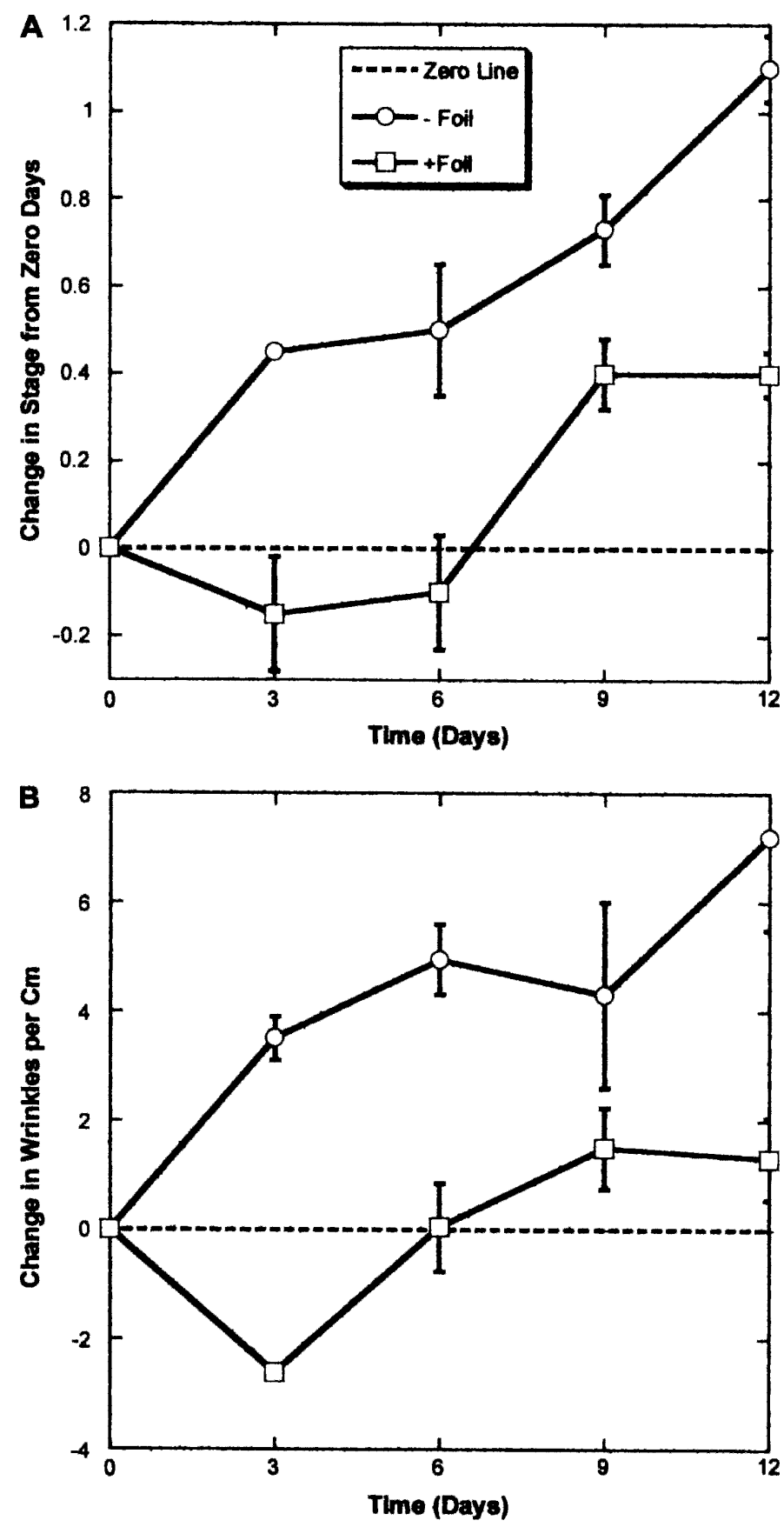

Fig. 5. Covering the Easter lily bulblet with aluminum foil suppresses the root contraction, whether measured as the progressive changes in stage (A) or as the amount of wrinkles associated with contraction (B). Circles, controls in light; squares, bulblets darkened by aluminum foil.

Stage IV roots because most of the contraction had already occurred when the experiment started.

Another aspect of the light control could involve the photoperiod. Bulblets were illuminated with photoperiods ranging from 1 to $24 \mathrm{~h} \cdot \mathrm{d}^{-1}$, for $6 \mathrm{~d}$. The data in Fig. 7 show a linear increase in root contraction with the daily light period, whether measured as the advance in stage or as wrinkle density.

The effectiveness of light in stimulating root contraction raises a question about the nature of the light receptor. Initial experiments addressing this question were carried out with continuous light of different wavelength regions for $8 \mathrm{~d}$. The 

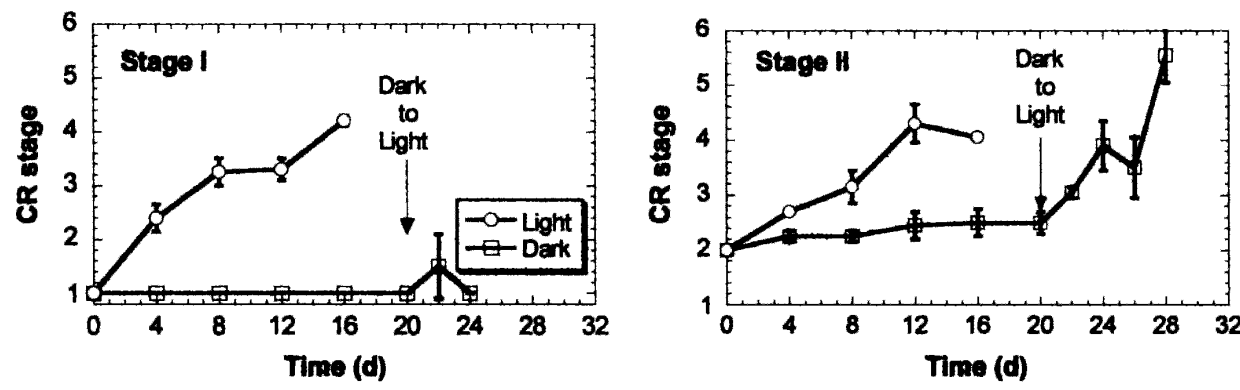

with a shortening of the initially linear cortical cells to a wider and shorter configuration. Shortening could possibly be initiated by swelling. The root shortening is triggered by a perception of light. The sensing of the light regulatory action occurs not in the contractile root, but in the bulblet or, possibly, by an emerging leaflet arising from the bulblet. In either event, the light effect is
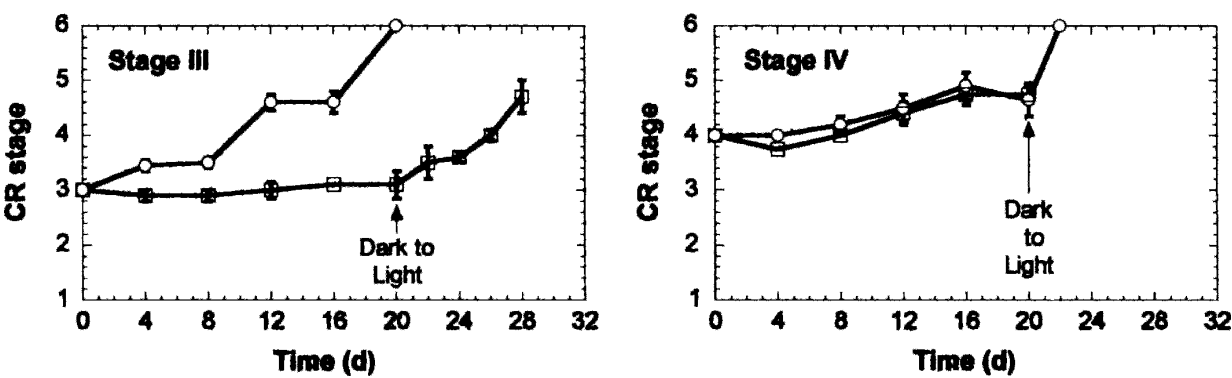

Fig. 6. Stimulation of Easter lily root contraction by light depends upon the stage of the root at time of light treatment, and by a preceding period of darkness. The greatest response to light was obtained for roots in Stage I and lessened progressively for Stages II, III, and IV. Light applied after $20 \mathrm{~d}$ of darkness (Stage IV) was much less stimulative of contractions.

advancement of root contraction under five different light regimes is given in Fig. 8. Under exposure to blue light, contraction had advanced to Stage 1.9, whereas under ultraviolet, green, red, or far-red light, contraction proceeded to less than Stage 1 (i.e., Stage 0.5). While there were differences in fluence rate for the various filters, blue light was markedly more active in stimulating root contraction than the other spectral regions.

\section{Discussion}

The downward movement of the bulblets of Easter lily occurs as a function of the action of CR. Root contraction involves changes in cellular configuration in the cortical tissue,

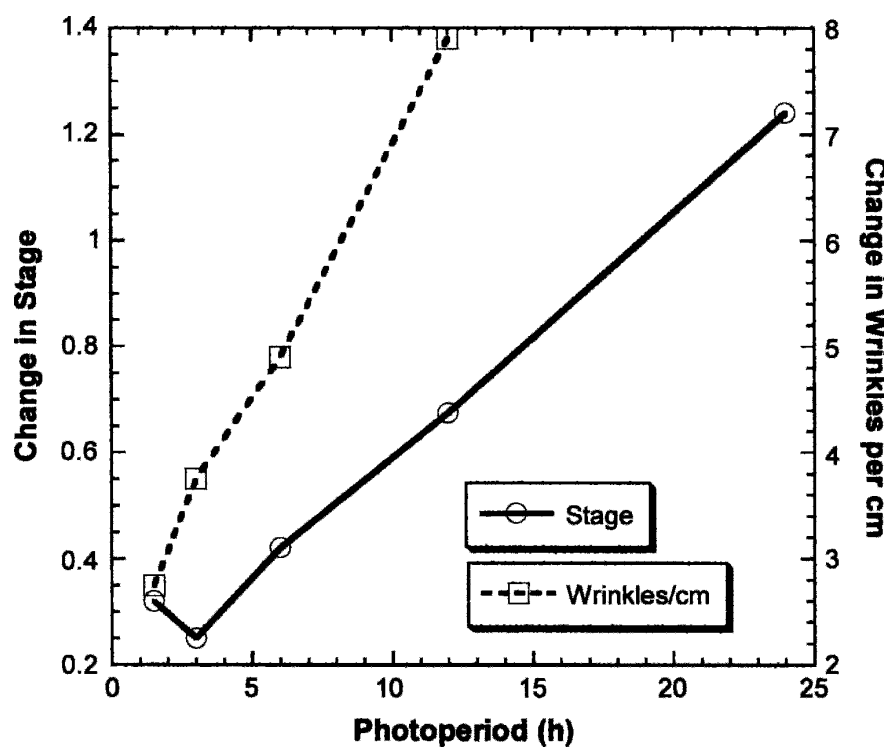

Fig. 7. With longer daily photoperiods, there are increases in the contraction response of Easter lily roots, whether measured as advance in stage (solid line) or as changes in amount of wrinkles per centimeter (dashed line). prompted by a light gradient down through the medium seems challenging. However, there are precedents of light-regulated events claimed to occur at similar soil depths (Wesson and Waring, 1969). Measurable light penetration through soil has indicated a maximum penetration of $1 \mathrm{~cm}$ (Barnett and McGilvary, 1997; Mandoli et al., 1990; Tester and Morris, 1987).

The sensing of the signal for root contraction is at present unclear. In some bulbous species, light has been shown to be perceived by the leaflet base, as in Oxalis bowieana Lodd. (Iziro and Hori, 1983), Sauromatum guttatum Well. (Putz et al., 1997), and Narcissus tazetta L. and Nothoscordum inodorum Kunth. (Putz, 1996b). Contractility in Leopoldia maritima L. is triggered by temperature cycling in the soil (Galil, 1958). In Hemerocallis fulva L., contractility has been claimed to occur as a component of growth (Putz, 1998). Interestingly, in this latter instance, roots can either pull the tuber down or they can push the tuber upward in the event that it is located too far down in the soil.

Contraction in Easter lily roots occurs in response to total daylength rather than in response to cyclic periods, as in Gladiolus L. (Jacoby and Halevy, 1970).

As a preliminary effort to identify the photoreceptor, the use of different light qualities indicates that contraction is especially responsive to blue light, suggestive of the blue-light reactions of Briggs and Huala (1999). This contrasts with that in Gladiolus, which responds only to high-fluence red light (Jacoby and Halevy, 1970).

Although we do not see a role for the root cap in Easter lily contraction, the root cap can signal a decrease in root elongation in pea (Pisum sativum L.) and maize (Zea mays L.) (Eliasson and Bollmark, 1988; Torrey, 1952; Wilkins and Wain, 1974). It may be noted that in pea tendrils, blue light also induces ventral cell contraction, which is an initial component of response to mechanical perturbation (Shotwell and Jaffe, 1979).

If the Easter lily bulblet has not yet reached the optimum depth, new CR are formed and extend the movement (Table 1). 


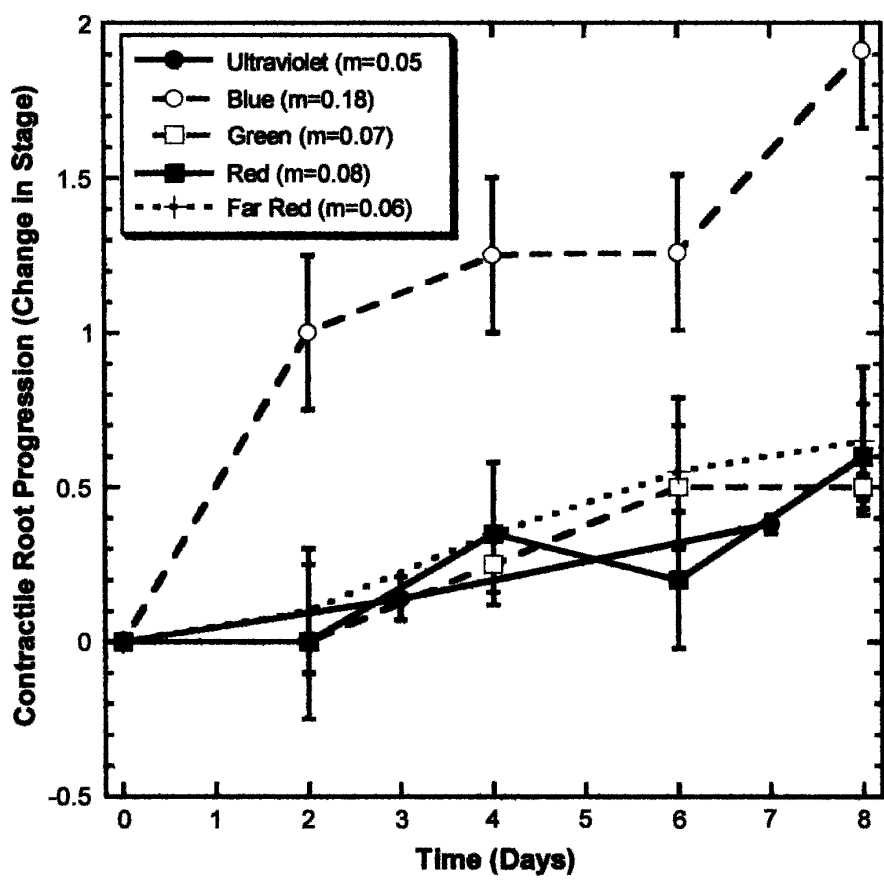

Fig. 8. Contraction of Easter lily roots is strongly activated by blue light as compared with ultraviolet, green, red, or far-red light. Light was applied continuously for $8 \mathrm{~d}$. Intensity varied with the color filter used (UV-A = $0.17 \mu \mathrm{mol} \cdot \mathrm{m}^{-2} \cdot \mathrm{s}^{-1}$, blue and far red $=0.25 \mu \mathrm{mol} \cdot \mathrm{m}^{-2} \cdot \mathrm{s}^{-1}$, green and red $=$ $\left.0.76 \mu \mathrm{mol} \cdot \mathrm{m}^{-2} \cdot \mathrm{s}^{-1}\right)$

There appears to be a continuous cycling of CR until the bulblet reaches a given depth in the soil. The involvement of multiple roots is quite different from the CR seen in Gladiolus, which has only one CR whose diameter is larger than the geophyte (Halevy, 1986).

As the Easter lily CR reaches its maximum contraction, it undergoes autolysis via the programmed cell death of the cortex. We suggest that both the swelling and later cell death of the cortex cells may be triggered by ethylene, which has been shown to cause both types of effects in some other species (Baskin and Bivens, 1995; Drew et al., 1979). The amount of contraction can be considerable. In the basal, contracting portion of the root, the length can be reduced to 0.45 times its original length (see Results, above). In roots from scales planted $1 \mathrm{~cm}$ below the surface, the contracted (wrinkled) length of the root base was $9.1 \pm 0.4 \mathrm{~mm}$. Thus, by calculation, the bulblet should have been pulled down at $\approx 11.3 \pm 0.6 \mathrm{~mm}$ (20.4 to 9.1 $\mathrm{mm})$. This amount is not greatly different from the observed descent of $9.3 \pm 0.6 \mathrm{~mm}$ (Fig. 4). Consecutive arrays of CR (Table 1) can move the bulb as much as 10 or $15 \mathrm{~cm}$ down into the soil.

Bulb movement into various depths of the soil has been reported as ca. $15 \mathrm{~cm}$ in Crocus sativus L. (Negbi et al., 1989), $\approx 23 \mathrm{~cm}$ or more in Leontice leontopetalum L., Bongardia chrysogonum Mirb., and Astoma sesilifoluim Burchell (Halevy, 1986).

The dramatic change in cell form during root contraction was suggested by DeVries (1880) to be due to a change in the synthesis of new cell walls. Smith-Huerta and Jernstedt (1989) and Smith-Huerta (1990) showed that in hyacinth (Hyacinthus orientalis L.) there are changes in the orientation of cell wall microfibrils with contraction, and that the microtubules change as well. The swelling of cells can occur in response to ethylene (Apelbaum and Berg, 1971; Lang et al., 1982).
The contraction of Easter lily roots is preceded by a swelling of the cortical cells of the root, not concomitant with it, as has been noted in other species (Esau, 1965; Putz, 1996a, 1996b). There is an early disappearance of nuclei in the cortical cells (data not shown). As the CR has finished contracting, lacunae become visible, until the root ultimately becomes a brownish dead sack composed of the epidermis and the exodermis containing the stele cylinder.

The question of how the bulblet determines its optimal depth is not answered. Because a light gradient seems unlikely, another explanation is needed. It is possible the etiolated elongating leaflet is involved in depth perception. Thus, the amount of donation of resources to leaflet growth by the bulblet (Iziro and Hori, 1983b) may participate in regulation of the depth to which the bulblet is pulled down, as suggested by Rimbach (1898).

In summation, the movement of underground parts in Easter lily appears to be driven by contractile growth in specialized roots. This is structurally achieved by changes in cell shape, perhaps with associated changes in hydraulics. This type of contraction contrasts with animal systems where movement generally involves contractile proteins. We also find it intriguing that, of the several species in which bulb movement has been studied, there is a remarkable range of physiological signals that can be employed to accomplish the same end: formation and function of CR.

\section{Literature Cited}

Apelbaum, A. and S. Berg. 1971. Altered cell microfibrillar orientation in ethylene treated Pisum sativum (L.) stems. Plant Physiol. 48:648652.

Barnett, J.P. and J.M. McGilvary. 1997. Guidelines for producing longleaf pine seedlings in containers. Gen. Tech. Rept. SRS-14. U.S. Dept. Agr. For. Serv., Southern Res. Sta., Asheville, NC.

Baskin, T.I. and N.J. Bivens. 1995. Stimulation of radial expression in Arabidopsis L. roots by inhibitors of actomyosin and vesicle secretion but not by various inhibitors of metabolism. Planta 197(3):514-521.

Briggs, W.R. and E. Huala. 1999. Blue-light photoreceptors in higher plants. Annu. Rev. Cell Dev. Biol. 15:33-62.

De Vries, H. 1880. Über die Kontraction der Würzeln. Landwirtsch. Jahrb. Z. Wissensch. Landwirtsch. Arch. Königl. Preuss. LandesOekon.-Kollegiums 9:37-80.

Drew, M.C., M.B. Jackson, and S. Gifford. 1979. Ethylene-promoted adventitious rooting and development of cortical air spaces (aerenchyma) formation in adventitious roots of Zea mays L. subjected to exogenous ethylene or to oxygen deficiency. Planta 147:8388.

Eliasson, L. and M. Bollmark. 1988. Ethylene as a possible mediator of light-induced inhibition of root growth. Physiol. Plant. 72:605609.

Esau, K. 1965. Plant anatomy. Wiley, New York.

Galil, J. 1958. Physiological studies on the development of contractile roots in geophytes. Bul. Res. Council Israel 6D:221-236.

Galil, J. 1980. Kinetics of bulbous plants. Endeavour 5:15-20.

Gray, P. 1958. Handbook of basic microtechnique. McGraw-Hill, New York.

Halevy, A.H. 1986. The induction of contractile roots in Gladiolus grandiflorus (Van Houtte). Planta 167:94-100.

Iziro, Y. 1983a. Effect of temperature on the growth of contractile $\operatorname{root}(\mathrm{s})$ and daughter corm or bulbs in Gladiolus and Oxalis bowieana. (Lodd.). J. Jpn. Soc. Hort. Sci. 51:459-465.

Iziro, Y. and Y. Hori. 1983b. Retranslocation of photoassimilates accumulated in contractile root(s) to daughter corm or bulbs in Gladiolus and Oxalis bowieana (Lodd). J. Jpn. Soc. Hort. Sci. 52:56-64. 
Jacoby, B. and A.H. Halevy. 1970. Participation of light and temperature fluctuations in the induction of contractile roots of Gladiolus. Bot. Gaz. 131:74-77.

Lang, J.M., W.R. Eisinger, and P.B. Green. 1982. Effects of ethylene on the orientation of microtubules and cellulose microfibrils of pea epicotyl cells with polylamellate cell walls. Protoplasma 110:5-14.

Leopold, A.C. and M.J. Jaffe. 2000. Many modes of movement. Science 288:2131-2132.

Mandoli, D.F., G.A. Ford, L.J. Waldron, J.A. Nemson, and W.R. Briggs. 1990. Some spectral properties of several soil types: implications for photomorphogenesis. Plant Cell Environ. 13:287-294.

Negbi, M., B. Dagan, A. Dror, and D. Basker. 1989. Growth, flowering, vegetative reproduction, and dormancy in the saffron crocus (Crocus sativus L.). Isr. J. Bot. 38:95-113.

Putz, N. 1996a. Underground plant movement. III. The corm of Sauromatum guttatum (Wall.) Schott. Flora 191:275-282.

Putz, N. 1996b. Underground plant movement. IV. Observance of the behaviour of some bulbs with special regard to the induction of root contraction. Flora 191:313-319.

Putz, N., J. Pieper, and H.A. Froebe. 1997. The induction of contractile root activity in Sauromatum guttatum (Araceae). Bot. Acta 110:49-54.

Putz, N. 1998. Underground plant movement. V. Contractile root tubers and their importance to the mobility of Hemerocallis fulva (L.). Int. J. Plant Sci. 159:23-30.

Rimbach, A. 1898. Die kontraktilen Würzeln und Ihr Thätigkeit. Beitr. Wissensch. Bot. 2:1-27.
Rimbach, A. 1902. Physiological observations on the subterranean organs of some Californian Liliaceae. Bot. Gaz. 33:401-420. Rimbach, A. 1926. Die Grosse der Würzelverkurzung. Ber. Dtsch. Bot. Ges. 44:328-334.

Shotwell, M. and M.J. Jaffe. 1979. Physiological studies on pea tendrils. X. Characterization of the light activation effect on contact coiling as a blue light trigger. Photochem. Photobiol. 29:1153-1156.

Smith-Heurta, N.L. 1990. Root contraction in hyacinth. IV. Orientation of cellulose microfibrils in radial longitudinal and transverse cell walls. Protoplasma 154:161-171.

Smith-Heurta, N.L. and J.A. Jernstedt. 1989. Root contraction in hyacinth. III. Orientation of cortical microtubules visualized by immunofluorescence microscopy. Protoplasma 151:1-10.

Tester, M. and C. Morris. 1987. The penetration of light through soil. Plant Cell Environ. 10:281-286.

Theophrastus. 300 BCE. Enquiry into plants (English translation by A. Hort, 1990). Harvard University Press, Cambridge, MA.

Tittmann, D.J.A. 1819. Botanische-karoplogische Bemerkungen. Flora 2:651-664.

Torrey, J.G. 1952. Effects of light on elongation and branching in pea roots. Plant Physiol. 27:591-602.

Wesson, G. and P.F. Waring. 1969. The induction of light sensitivity in weed seeds by burial. J. Expt. Bot. 20:413-425.

Wilkins, H. and R.L. Wain. 1974. The root cap control of root elongation in Zea mays L. seedlings exposed to white light. Planta 121:1-8. 